\title{
Exploring the Built Environment Factors in the Metro That Influence the Ridership and the Market Share of the Elderly and Students
}

\author{
Jiang Ning $\mathbb{D},{ }^{1}$ Tao Lyu $\mathbb{D}^{2},{ }^{2}$ and Yuanqing Wang $\mathbb{D}^{2}$ \\ ${ }^{1}$ School of Traffic and Transportation, Lanzhou Jiaotong University, Lanzhou 730070, China \\ ${ }^{2}$ College of Transportation Engineering, Department of Traffic Engineering, Chang'an University, Xi'an 710064, China
}

Correspondence should be addressed to Yuanqing Wang; wyqing@chd.edu.cn

Received 25 March 2021; Accepted 4 October 2021; Published 13 November 2021

Academic Editor: Hongtai Yang

Copyright (c) 2021 Jiang Ning et al. This is an open access article distributed under the Creative Commons Attribution License, which permits unrestricted use, distribution, and reproduction in any medium, provided the original work is properly cited.

\begin{abstract}
The metro has developed rapidly in the past two decades and has become one of the crucial patterns of transportation for urban residents in China. Many studies have explored the factors affecting metro ridership, but few have focused on the metro usage of specific groups, such as the elderly and students. This paper uses the negative binomial regression model to explore the relationship between the built environment and the metro ridership of three types of people (adults, the elderly, and students) by using the metro smart card data of Qingdao. We also used the fractional response model to discuss the factors that influence the ridership share for the elderly and students. The results show that most variables promote the metro usage of the three groups of people but have a significantly different effect on the market share of those groups. Specifically, the number of schools, hospitals, supermarkets, squares, parks, and scenic spots near metro stations significantly increases the proportion of the elderly metro usage. The number of bus stops and schools substantially increases the share of metro ridership by students. The research results can provide valuable insights for promoting the metro's overall ridership and minimizing the gap in allocating public transport resources among different groups.
\end{abstract}

\section{Introduction}

With the rapid development of urbanization, many problems such as traffic congestion and environmental pollution have become increasingly prominent. To solve this series of social and environmental problems, an increasing number of Chinese cities have begun to develop or expand rail transit systems [1]. As of the end of 2020, 45 cities in China have opened rail transit, with a total operating mileage of $7969.7 \mathrm{~km}$, of which the metro mileage is $6280.8 \mathrm{~km} \mathrm{[2].}$

To adapt to the rapid development of the metro system, many researchers began to predict and explore the factors affecting metro ridership to formulate metro development and operation plans. The most widely used ridership models are the general four-step model [3] and activity-based model $[4,5]$. Although these models can quantify urban passenger demand well, they have disadvantages such as higher cost and lower accuracy [6-8]. In recent years, with the continuous development of geographic information systems (GIS), a large number of studies have adopted statistical models such as the ordinary least squares (OLS) regression model [9], structural equation model (SEM) [10], and direct ridership models (DRMs) [11], combined with urban built environment to explore the factors influencing metro ridership. Compared with traditional models, they are simple, straightforward interpretation of results, and cost less.

However, most studies have taken total ridership as the research object, but only a few studies have explored the use of the metro by specific groups such as the elderly and students. Affected by unfavorable factors such as physiology and economic income, specific groups have more urgent public transportation demands than mainstream adults. With the widespread use of smart card data, many researchers use card types to classify passengers and explore 
the travel characteristics and differences between mainstream and other groups $[12,13]$. However, these studies are based on bus data and do not involve the metro usage of specific groups. In addition, policy recommendation is more valuable when exploring the travel patterns and preferences of multiple groups of people using the metro at the same time. Therefore, this paper uses metro smart card data to explore the metro usage by adults and other groups (the elderly and students) to fill the gaps in the research content of this direction.

The structure of this study is arranged as follows: Section 2 reviews related literature. Section 3 describes the study area and data. Section 4 introduces the research method, and Section 5 presents the research results and discussion. Section 6 summarizes the conclusion and limitations.

\section{Literature Review}

Numerous previous studies exist on the travel behavior of the elderly and the travel mode choices of students to go to school. However, few studies have focused on the metro travel behaviors of the elderly and students. Therefore, this section will review this literature as references.

2.1. Elderly People. As problems of aging continue to intensify, it is crucial to maintain the sense of social participation and mobility of the elderly [14-17]. As with the mainstream population, the built environment affects the travel modes of the elderly [18-20]. Studies have shown that neighborhood design characteristics are closely related to the active travel mode of the elderly. For instance, older adults will have more active travel in highly walkable neighborhoods [21]. At the same time, uneven sidewalks, pot-holes, and other harsh walking environments will affect both the accessibility and mobility of older adults [22]. Since most older adults have retired, they have more time to engage in nonwork activities. Compared with young people, their mobility may not have been significantly reduced [17]. Meanwhile, due to the Chinese cultural background and practical needs, the elderly living with their adult children also have other out-of-home activities under family responsibilities [19]. For example, compared with others, older people with many family members may have more bus trips because they often help take children to school [23].

Previous studies have shown that Western older adults have strong car dependence $[24,25]$. Affected by the economic development level and social background, the accessibility of public transportation is an essential determinant of the travel behavior of the elderly in China [19]. For example, a study in Nanjing showed that the number of bus stops and bike share stations has a positive effect on the travel frequency of the elderly [18]. As an important pattern of travel for the elderly, public transportation also helps to improve the accessibility and fairness of the elderly to deal with the unbalanced distribution of urban public service facilities. For instance, compared with the elderly in urban areas, the elderly living in suburbs have a longer distance to get medical treatment and are more dependent on public transportation [26].
To further protect the well-being of the elderly, many Chinese cities have adopted various preferential policies to encourage the elderly to use public transportation: discounted fares and monthly public transportation subsidies. Although these policies have effectively encouraged the use of public transport, the effect may be quite limited. A study in Beijing showed that free bus programs for the elderly only induced less than $5 \%$ of bus trips among older adults [23]. Therefore, to further attract more elderly people to use public transportation to maintain their necessary mobility, in addition to public transportation preferential policies, we also need to consider how to increase the attractiveness of public transport to the elderly from other perspectives.

2.2. Elementary and Middle School Students. Going to school is the leading travel activity for elementary and middle school students ( 6 to 18 years old). A large number of studies have shown that the built environment is closely related to the students' trip pattern of going to school [27-30]. First, the distance between home and school is the main factor. The increase in travel distance will prompt students to switch from active travel mode to motorized mode. An Irish study indicated that $2 \mathrm{~km}$ is the dividing line between motorized and nonmotorized modes for students [31]. A Chinese study showed that as the distance of travel increases, students would switch from walking to riding a bicycle. When the travel distance exceeds $3 \mathrm{~km}$, they will use more public transportation and private cars to go to school [32]. Second, the number of street intersections is also related to the students' school transportation patterns. A small number of intersections will encourage children with shorter travel distances to use active travel mode, but the increased intersection number will affect the comfort of the journey and reduce the propensity of students with longer travel distances to use public transportation [29]. Third, students' travel patterns are closely related to the local geography and culture. Due to Finnish cycling culture and developed cycling infrastructure, $43 \%$ of students cycle to school in Helsinki [27]. In Hong Kong, due to safety and topographical issues, students rarely ride bicycles to school, and their main travel modes are walking and school buses [33]. Finally, due to a long commuting distance and complicated urban transportation system, a single traffic vehicle may not meet the commuting needs of students. The only study about students commuting by the metro shows that the density of bus stops and docks at bike share stations positively affects students who use the metro to travel [30]. This means the connectivity of transportation also affects the travel pattern of students.

Many studies recommend that students use active mode to school to protect their health and ease urban traffic congestion [29, 34]. However, some Western and Chinese studies have shown that the existing urban education system is unfair. Many students start to go to schools farther away to obtain higher-quality educational resources $[29,35,36]$; it is essential for them to use safe and reliable transportation. Limited by operational efficiency and inadequate supervision and management, the school bus system in China is not 
yet mature [30]. Therefore, besides private cars, public transportation is a significant pattern for students who have long commutes to school.

2.3. Literature Summary. In summary, the existing literature focuses on the influence of the built environment on the travel of the elderly and students. Still, the relationship between these factors and metro ridership of the elderly and students has not been explored. Therefore, the paper uses the smart card and built environment data to analyze the travel behavior of adult, the elderly, and student metro usage by the negative binomial regression model. In addition, considering the importance and necessity of public transportation for these groups, we also used the panel data model framework to explore the factors affecting the market share of specific groups to improve their transportation equity. This result can evaluate the built environment preferences of the elderly and students' metro usage and provide valuable insights into route planning and station design.

\section{Study Area and Data}

3.1. Study Area. Qingdao is a subprovincial city located in Shandong Province, an important central city and international port city along the coast of China. Qingdao's permanent population was 9.50 million in 2019, of which 6.45 million lived in the urban area, including 2.20 million older adults and 0.99 million elementary and middle school students [37]. Qingdao's built-up area was $758.16 \mathrm{~km}^{2}$, and the urbanization rate was $74.12 \%[37,38]$. There are two main reasons for choosing Qingdao as the research object. First, Qingdao is the second Chinese batch of selected "transit metropolis" model cities, with a relatively developed metro system. The city has already built and operates four metro lines by the end of 2019 . The total length of the metro network is $176 \mathrm{~km}$ and includes 82 stations, and an annual passenger capacity of 187 million. Second, Qingdao provides excellent preferential policies to encourage the elderly and students to use public transportation. Elementary and middle school students and older adults (60 to 64 years old) can take the bus and metro at half price. The elderly of 65 and above can take free public transportation. Therefore, Qingdao is an excellent case for this research to explore the metro usage of the elderly and students. The study area includes the main urban areas of Shinan, Shibei, Licang, Laoshan, and the urban areas of Huangdao and Jimo covered by the metro network. The metro network of Qingdao is shown in Figure 1.

\subsection{Data}

3.2.1. Data Processing. To explore the built environment's influence on the metro usage of three groups of people, this study used the Qingdao Metro smart card and built environment data.

We use Qingdao Metro smart card data from 13/5/2019 (Monday) to 19/5/2019 (Sunday). The data come from Qingdao Metro Company. Due to route planning issues, 3 stations were not yet operational at that time. Therefore, this study includes card transaction data generated by 79 stations. After a passenger enters the station and swipes a card, a data set will be generated, including passenger card number, card type, transaction date, and transaction time. See Table S1 in Supplementary Material for the metro smart card data structure. Since passengers need to swipe their cards to enter and exit the metro station, the two transaction records represent one trip.

The Qingdao Metro smart card types mainly include regular cards, old age cards, and student cards. The old age card is only for adults aged 60 and above. The student card is used only by school students under 18. In this study, we used only regular cards, old age cards, and student cards and used these card types to represent adults (18-59 years old), the elderly, and students, respectively.

The original data of Qingdao Metro in one week included a total of 6.04 million transaction records. After deleting some records that had errors or were incomplete, we extracted the card types corresponding only to the three groups. Our data set included 3.314 million metro transactions, accounting for $54.9 \%$ of the original data. In the data set, adults, the elderly, and students, respectively, have 2.620 , 0.489 , and 0.205 million transaction records. The elderly and students, respectively, accounted for $14.8 \%$ and $6.2 \%$ of the data set. This proportion is much smaller than the actual proportion of the elderly and elementary and middle school students in Qingdao $(14.8 \%<23.2 \%, 6.2 \%<10.4 \%)$. The result means the elderly and students are far less likely to use the metro than adults.

In this paper, we used point of interest (POI) data collected from the Baidu map to represent the built environment. We selected the explanatory variables as follows. First, we extracted the characteristics of metro stations and used them to measure which type of metro station people like to use. Specifically, four factors were considered: bus stops, road intersections, metro station entrances/exits, and whether the station is in the main urban area. Second, considering people's travel purpose, we further chose the following variables: extracted the hospitals, squares, and parks to represent their medical and leisure demands and selected the scenic spots and supermakets to represent their entertainment and shopping demands. In addition, we extracted elementary and middle schools to represent students' daily commuting purposes. The descriptive statistics of variables are shown in Table 1. All variables related to numbers were calculated within an $800 \mathrm{~m}$ distance from each metro station, which is considered the standard distance and is often used to delimit the buffer of metro stations $[1,39]$.

3.2.2. Data Analysis. We divided the metro operating period $(6: 00-23: 00)$ into 16-time intervals and calculated the travel time distribution of adults, the elderly, and students, as shown in Figure 2. The three groups of people have obvious morning and evening peak travel characteristics but are slightly different. Specifically, the adults have more trips in the morning peak than in the evening peak. For the elderly, 


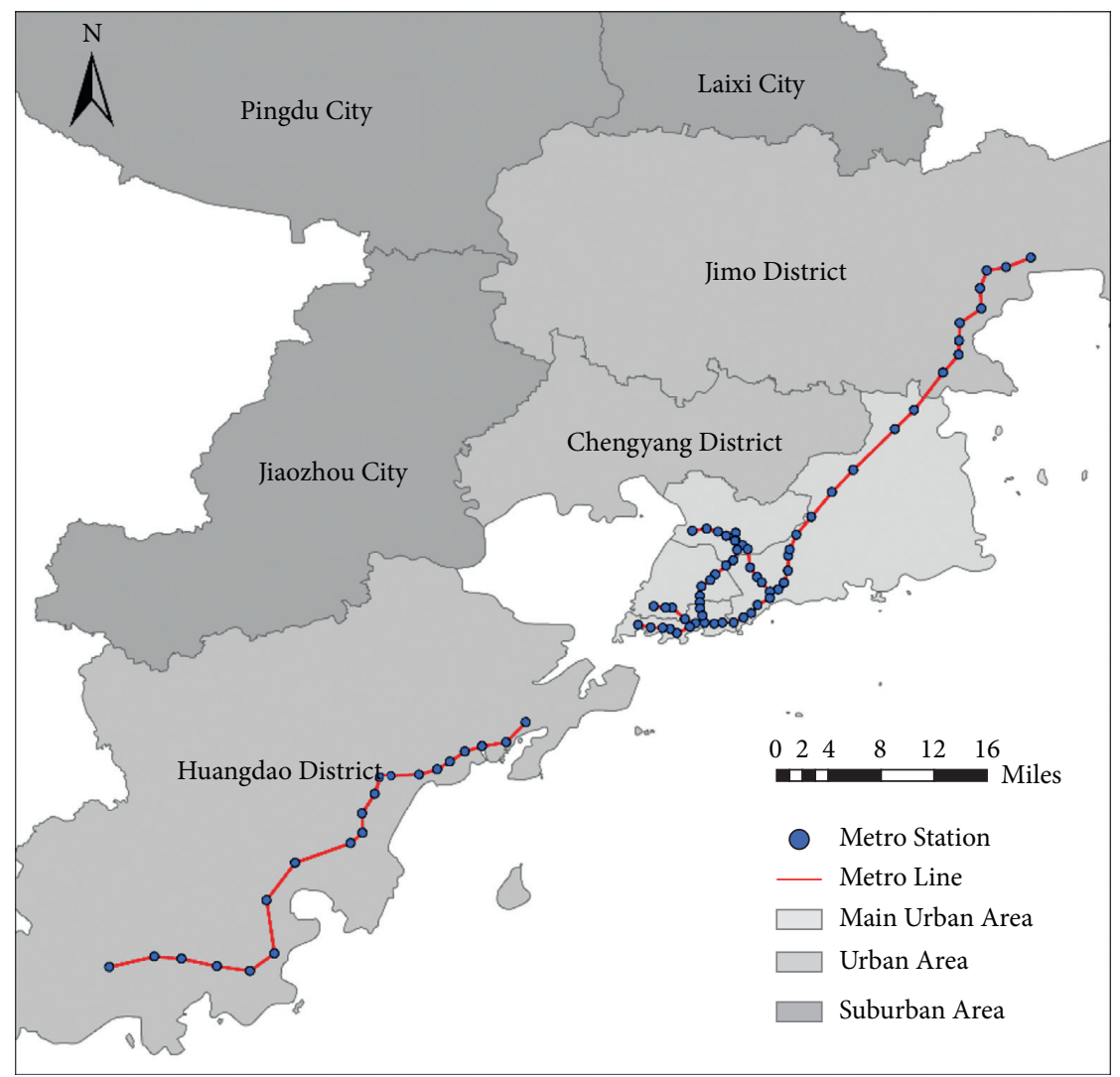

FIgURE 1: The metro network of Qingdao.

the most frequent trips are from 7:00 to $11: 00$ in the whole day, as well as the proportion of trips between $11: 00$ and 15: 00 is higher than that in other groups. This travel characteristic is because most older adults have retired and their schedule is more flexible. The travel time distribution of students is roughly similar to adults, but there are still two differences. The first is that students' morning and evening peaks are earlier than adults because they go to school/leave school earlier than adults go to work/off work. Second, the proportion of their trips in the morning peak is less than that in the evening peak because some parents drive their students to school in the morning [29]. These students need to take other transportation to get back home by themselves in the evening.

Station-level metro ridership composition is shown in Figure 3. In general, the composition of passengers in different stations has a significant difference. Specifically, stations with a high proportion of adults traveling are mainly concentrated in the main urban area because this area has a high job density. Adults have a lot of commuting demands at these stations. Quite differently from the stations with a high proportion of adults, the stations with a high proportion of elderly travelers are mainly located in the northeast and southwest areas of Qingdao, far away from the city center. This can be explained in two ways. First, a previous study shows that both adults and the elderly in Qingdao prefer to travel in main urban areas, but the total amount of adult travel is much more than that of older adults [12]. Therefore, from the overall ridership composition, the urban elderly's share of trips is relatively low. Second, as there are many tourism resources along with the metro in the southwest and northeast of Qingdao, this may attract many elderly passengers. Students have a higher proportion of trips at the stations on the west coast of Qingdao. This may be because the educational resources in the Huangdao district are more concentrated than that in other regions, attracting much ridership by students along metro lines.

\section{Method}

4.1. Negative Binomial Regression Model. The aim of this paper is to explore the influence of station characteristics and city facilities on the metro usage of adults, the elderly, and students because there is much more ridership in some metro stations than others; in other words, the sample data are too discrete and random. Therefore, we estimated the corresponding negative binomial regression model for three groups of people, which is widely used for data whose sample variance significantly exceeds the average and is overdispersed [40]. The negative binomial regression model can be described as follows:

$$
y_{i}=\exp \left(\beta_{0}+\sum_{j=1}^{n} \beta_{j} x_{i j}+\varepsilon\right),
$$

where $y_{i}$ represents the metro ridership of the $i^{\text {th }}$ metro station $i=(1,2,3, \ldots, m), \beta_{0}$ represents the intercept, $x_{i j}$ represents the $j^{\text {th }}$ independent variable of the $i^{\text {th }}$ metro 
TABLE 1: Descriptive statistics of variables.

\begin{tabular}{|c|c|c|c|}
\hline Variable & Description & Mean & Std. Dev. \\
\hline \multicolumn{4}{|l|}{ Station characteristics } \\
\hline Bus stops & Number of bus stops in $800 \mathrm{~m}$ buffer & 9.21 & 5.94 \\
\hline Road intersections & Number of road intersections in $800 \mathrm{~m}$ buffer & 3.36 & 2.53 \\
\hline Main urban area & 1: if the metro station in main urban area; 0 : otherwise & 0.65 & 0.48 \\
\hline Entrances/exits & Number of metro station entrances or exits in $800 \mathrm{~m}$ buffer & 2.90 & 1.22 \\
\hline \multicolumn{4}{|l|}{ City facilities } \\
\hline Schools & Number of elementary and middle schools in $800 \mathrm{~m}$ buffer & 1.68 & 2.07 \\
\hline Hospitals & Number of tertiary hospitals in $800 \mathrm{~m}$ buffer & 0.15 & 0.39 \\
\hline Supermarkets & Number of supermarkets in $800 \mathrm{~m}$ buffer & 0.64 & 1.50 \\
\hline Squares and parks & Number of squares and parks in $800 \mathrm{~m}$ buffer & 1.44 & 1.76 \\
\hline Scenic spots & Number of scenic spots in $800 \mathrm{~m}$ buffer & 0.21 & 0.40 \\
\hline
\end{tabular}

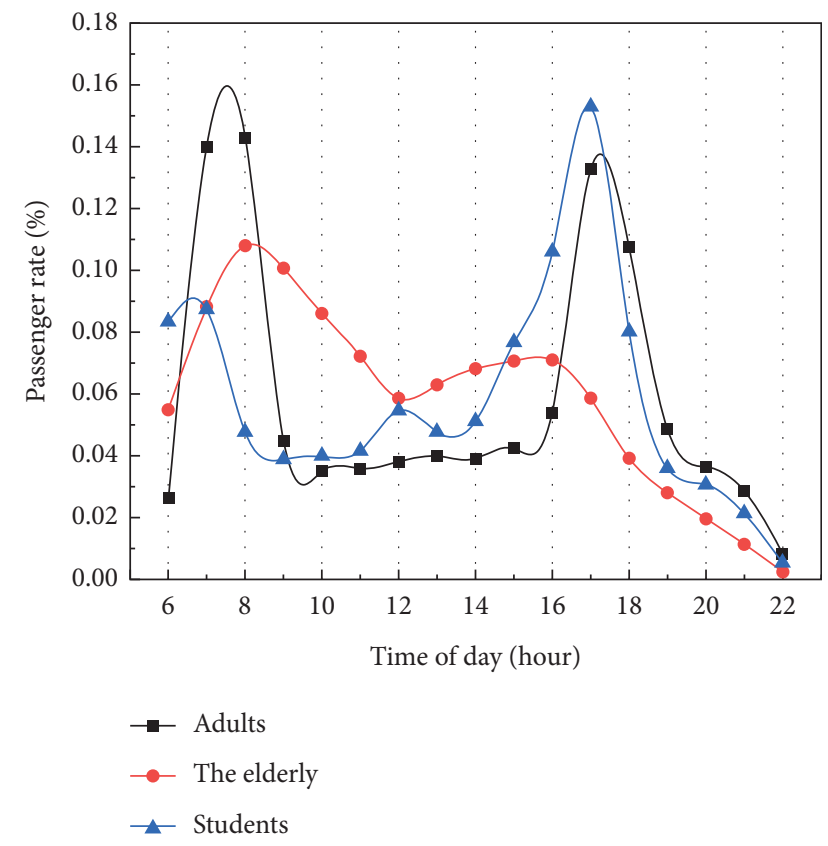

FIGURE 2: Proportion distribution of metro ridership among adults, the elderly, and students.

station $j=(1,2,3, \ldots, n), \beta_{j}$ is the regression coefficient of the $j^{\text {th }}$ independent variable, and $\varepsilon$ is the error term of the model and obeys the gamma-distribution.

4.2. Fractional Response Model. Our data set shows that compared with adults, the share of the elderly and students in the metro ridership is much smaller than their actual population. Therefore, we not only used the linear model to explore the influence of the built environment on the ridership of the three groups of people but also used the fractional response model to explore the determinants of the share of those groups in the metro ridership.

The fractional response model (also known as the fractional logit model) was first proposed by Papke and Wooldridge [41]. The model can effectively deal with bounded dependent variables and does not require additional calculations and is often used to explain models in which dependent variables such as share, pass rate, and proportion are between 0 and 1 . In recent years, this model has also gained some applicability in traffic research. For instance, McDonald used the fractional logit model to analyze the influence of the Safe Routes to School (SRTS) program on the proportion of students walking or cycling to school [42]. Wang used the fractional logit model to explore the difference in the influence of environmental factors on the share of trips made by men and women using bike share [43]. These studies have verified the advantages of the fractional response model compared with the linear model in dealing with bounded dependent variables. The structure of the fractional response model is as follows [41, 44]:

$$
E(y \mid x)=G(x ; \beta)
$$

where $G($.$) is a nonlinear cumulative function; the fitted$ value falls within the unit interval $[0,1]$. The fractional response model in the form of logistic function can be expressed as follows:

$$
E(y \mid x)=G(x ; \beta)=\frac{\exp (x \beta)}{1+\exp (x \beta)} .
$$

In this study, $x$ represents independent variables, and $\beta$ is the coefficient of the corresponding independent variable. $y$ is the dependent variable and represents the proportion of elderly and student trips to the total metro ridership. $y$ is calculated as follows:

$$
\begin{gathered}
y_{\text {the elderly }}=\frac{\text { metro ridership for the elderly }}{\text { total ridership of the metro }}, \\
y_{\text {student }}=\frac{\text { metro ridership for the student }}{\text { total ridership of the metro }} .
\end{gathered}
$$

To visually indicate the influence of selected variables on the market share of the metro by the elderly and students, we calculate the average elasticity effects (AEEs) for the built environment variables in the fractional response model. The elasticity effects represent the change in the market share of the metro ridership for the specific groups for every $1 \%$ increase in the dependent variable, while holding others constant. 


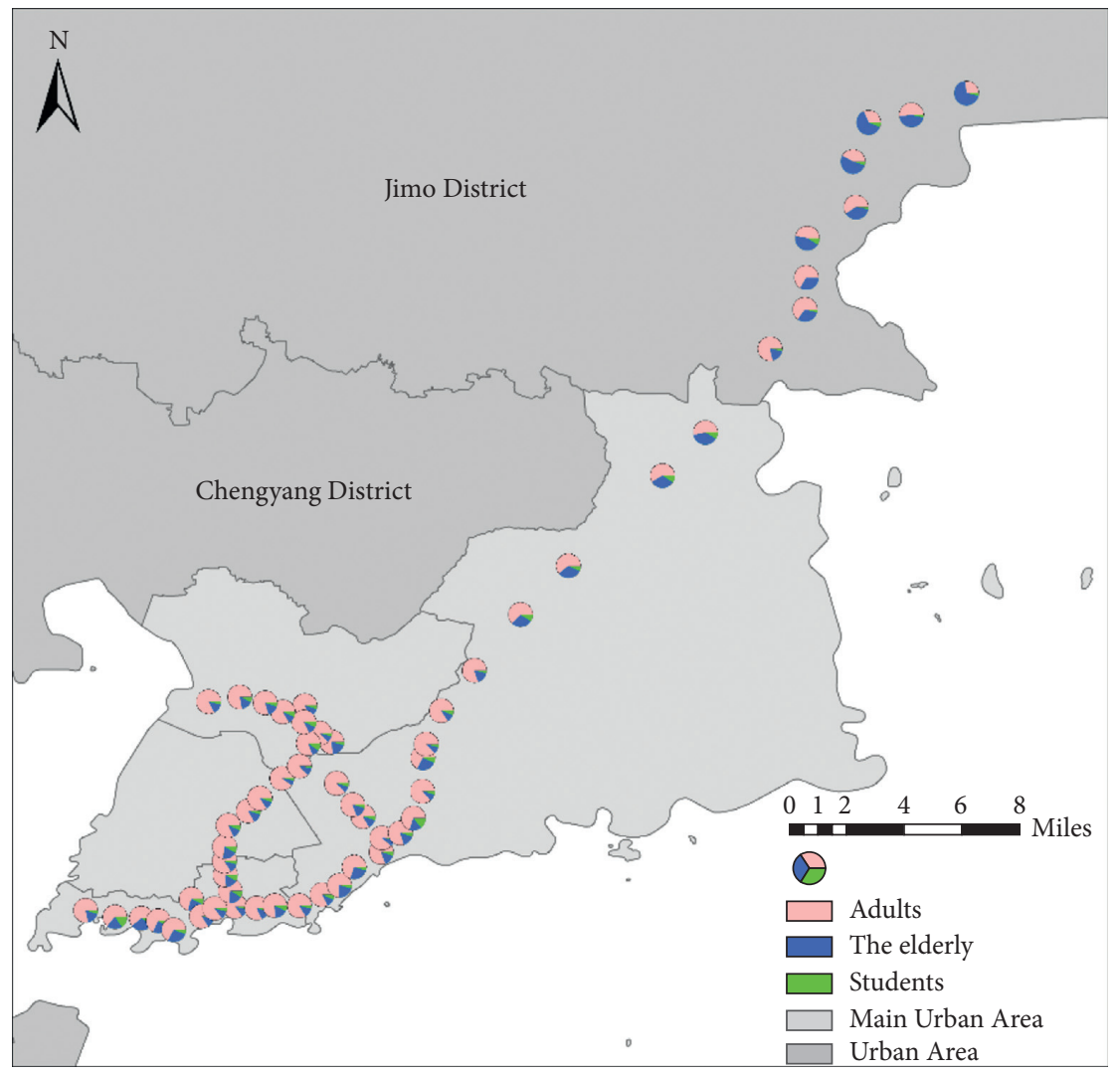

(a)

Figure 3: Continued.

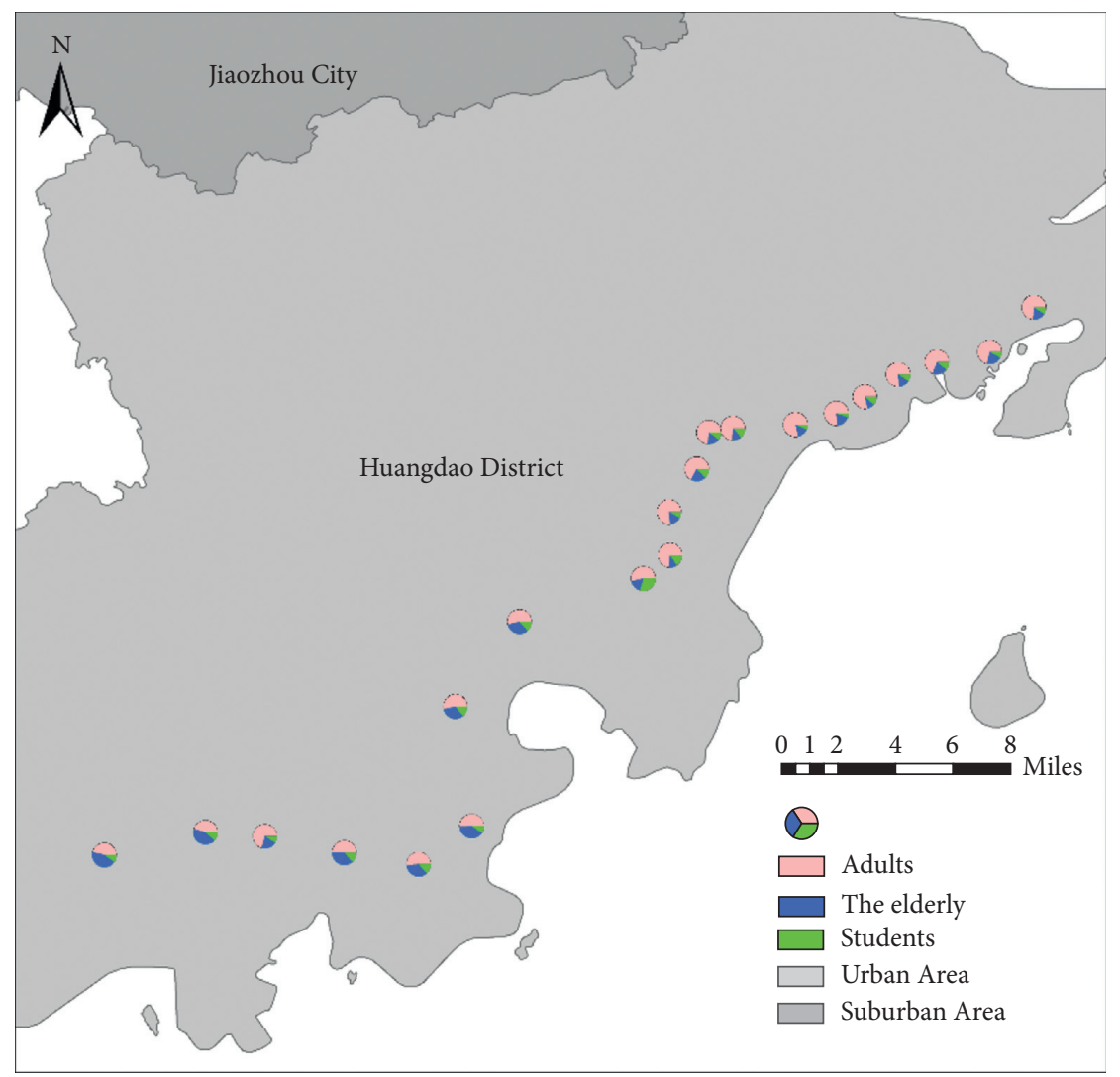

(b)

FIGURE 3: Station-level metro ridership composition of (a) east area and (station-level metro ridership composition of east area.) and (b) west area (station-level metro ridership composition of west area). 


\section{Results and Discussion}

Before establishing the models, we used the variance inflation factor (VIF) to check the collinearity of the variables and found that there was no collinearity among all the variables. Then, we retained the variables significant at the $95 \%$ level, and the model results are reported in Table 2. The first three models are negative binomial regression models, with the metro trips of three groups of people as the dependent variable. The latter two are fractional response models, with the proportion of elderly and student trips to the total ridership as the dependent variable. To encourage more old adults and students to use the metro and increase their market share, we will focus on the factors that influence metro usage by the elderly and students.

5.1. Station Characteristics. In our case, the number of bus stops will significantly enhance the attractiveness of the metro to adults and students. Moreover, the factor will have a positive effect on the trip share of students. The result is predictable because students usually use the bus as a feeder mode when they use the metro to go to school [30]. Therefore, higher bus stop densities help students transfer to the metro, thereby promoting the metro ridership by students. Previous studies generally demonstrate that bus stations positively correlate with metro ridership $[45,46]$. However, our results showed that this factor is a negative predictor of the share of the elderly metro trips. This may be because, compared with others, older people do not like transfer between metro and bus.

The results show that the number of road intersections is positively correlated with the metro ridership of adults, while it has a negative influence factor for the elderly. Moreover, we found the factor significantly reduces the share of the elderly. The results may mean that older people prefer metro stations with fewer intersections, which pedestrian environment may make them feel safe. However, we do not have more data to verify this hypothesis. Future research will continue to explore the influence of the pedestrian environment in the catchment area of metro stations on the elderly and students, such as road network density and road width.

In this study, the metro stations in the main urban area and the number of station entrances/exits are statistically significant and positively correlated with all groups. These results are interesting and can be explained by previous research. For the previous variable, Qingdao seniors prefer to travel in the old city [12], and most of the elementary and middle schools are located in the Qingdao main urban area [47]. Therefore, compared with the urban area, the metro stations located in the main urban area have more ridership of the elderly and students. For the latter variable, although previous studies have confirmed that the factor positively affects metro ridership [39], it is still unknown whether this factor affects the elderly and students. The research results verify and further expand the scope of this conclusion. Moreover, our research also found that these two variables have no positive effect on increasing the proportion of older adults and students. This may be because metro stations with these characteristics also attract a large number of adult travelers. Although the three groups of people have many trips in those stations, the adults have the most significant increase.

5.2. City Facilities. The number of elementary and middle schools is positively correlated with the metro ridership of adults and students and the share of trips made by students. Surprisingly, the factor has also significantly increased the elderly's metro usage and proportion. The result of the former is easy to understand. This latter finding can be explained by a previous study that found some older adults participate in some activities such as shopping in supermarkets and escorting children to school to support the older and younger generations in the family [17]. Thus, the number of schools is positively correlated with the number of trips and market share of the elderly and students. Moreover, the estimated margin effect shows that for every $1 \%$ increase in the number of elementary and middle schools near stations, the share of students in the metro ridership will increase by $0.31 \%$. The factor is most effective in increasing the proportion of students in metro ridership in all variables.

Regarding hospitals and supermarkets, we found that these two factors significantly increased the overall ridership but only positively influenced the proportion of the elderly. The result means that a large proportion of the ridership by the elderly meets their medical and shopping needs through the metro compared with other groups. Previous studies have verified that public transportation facilities positively influence the elderly's travel for medical treatment [26] and shopping [19]. Our research reconfirms these conclusions in terms of elderly metro usage.

The number of parks and squares is positively correlated with the ridership of the three groups of people. In addition, those factors have significantly increased the proportion of older adult metro usage. The result is not surprising. Because parks and squares are important leisure places for the elderly in China, they can meet various needs here, such as exercising and chatting with friends $[18,19]$.

Regarding scenic spots, we found the factor is positively associated with the elderly metro usage, as well as the share of the elderly. At the same time, we found the factor is negatively associated with the share of students' trips. This reason may be because many Chinese elderly have retired and have more free time to take the metro to visit the scenic spots. In contrast, students may not have much free time. Therefore, the variable only can significantly improve the use of the elderly. The estimated marginal effect shows that every $1 \%$ increase in the number of scenic spots in the metro catchment area leads to a $5.47 \%$ increase in the proportion of trips made by the elderly. Among the variables associated with the characteristics of the built environment, scenic spots have the greatest significant influence on increasing the market share of elderly metro usage. 
TABLE 2: Results for negative binomial regression models and fractional response model.

\begin{tabular}{|c|c|c|c|c|c|c|c|c|c|c|c|c|}
\hline & \multicolumn{6}{|c|}{ Negative binomial regression model } & \multicolumn{6}{|c|}{ Fractional response model } \\
\hline & \multicolumn{2}{|c|}{ Adults } & \multicolumn{2}{|c|}{ The elderly } & \multicolumn{2}{|c|}{ Students } & \multicolumn{3}{|c|}{ The elderly } & \multicolumn{3}{|c|}{ Students } \\
\hline & Coef. & $p$-value & Coef. & $p$-value & Coef. & $p$-value & Coef. & $p$-value & AEEs & Coef. & $p$-value & AEEs \\
\hline \multicolumn{13}{|c|}{ Station characteristics } \\
\hline Bus stops & 0.030 & $<0.001$ & & & 0.026 & $<0.001$ & -0.034 & $<0.001$ & $-0.56 \%$ & 0.007 & 0.047 & $0.04 \%$ \\
\hline Road intersections & 0.064 & $<0.001$ & -0.055 & $<0.001$ & & & -0.082 & $<0.001$ & $-1.34 \%$ & & & \\
\hline Main urban area & 1.240 & $<0.001$ & 0.671 & $<0.001$ & 0.474 & $<0.001$ & -0.259 & $<0.001$ & $-4.23 \%$ & -0.350 & $<0.001$ & $-2.19 \%$ \\
\hline Entrances/exits & 0.129 & $<0.001$ & 0.033 & 0.004 & 0.090 & $<0.001$ & -0.093 & $<0.001$ & $-1.51 \%$ & & & \\
\hline \multicolumn{13}{|l|}{ City facilities } \\
\hline Schools & 0.080 & $<0.001$ & 0.123 & $<0.001$ & 0.142 & $<0.001$ & 0.057 & $<0.001$ & $0.94 \%$ & 0.049 & $<0.001$ & $0.31 \%$ \\
\hline Hospitals & 0.157 & $<0.001$ & 0.267 & $<0.001$ & 0.313 & $<0.001$ & 0.064 & 0.014 & $1.05 \%$ & & & \\
\hline Supermarkets & 0.136 & $<0.001$ & 0.146 & $<0.001$ & 0.121 & $<0.001$ & 0.028 & $<0.001$ & $0.46 \%$ & -0.021 & 0.035 & $-0.13 \%$ \\
\hline Squares and parks & 0.083 & $<0.001$ & 0.087 & $<0.001$ & 0.066 & $<0.001$ & 0.019 & 0.009 & $0.32 \%$ & & & \\
\hline Scenic spots & -0.228 & $<0.001$ & 0.077 & 0.009 & \multirow{2}{*}{\multicolumn{2}{|c|}{0.813}} & 0.335 & $<0.001$ & $5.47 \%$ & -0.072 & 0.038 & $-0.45 \%$ \\
\hline Constant & \multicolumn{2}{|c|}{2.444} & \multicolumn{2}{|c|}{2.221} & & & \multicolumn{3}{|c|}{-0.548} & \multicolumn{3}{|c|}{-2.541} \\
\hline AIC & \multicolumn{2}{|c|}{100195.10} & \multicolumn{2}{|c|}{74839.33} & \multicolumn{2}{|c|}{56993.95} & \multirow{2}{*}{\multicolumn{3}{|c|}{$\begin{array}{l}9311.06 \\
9382.33\end{array}$}} & \multirow{2}{*}{\multicolumn{3}{|c|}{$\begin{array}{l}4545.48 \\
4616.75\end{array}$}} \\
\hline $\mathrm{BIC}$ & \multicolumn{2}{|c|}{100273.50} & \multicolumn{2}{|c|}{74917.73} & \multicolumn{2}{|c|}{57072.34} & & & & & & \\
\hline
\end{tabular}

AEEs refer to the average elasticity effects.

\section{Conclusions}

The metro is an essential infrastructure for alleviating traffic congestion and prompting the city's development. Exploring the factors that affect the metro ridership can help policymakers better formulate operational plans. This paper explores the travel characteristics and built environment preferences of specific groups (elderly and students) using the metro. The results verify findings from previous studies and provide new insights for improving the ridership of the elderly and students in station design and route planning.

Compared with adults, the share of the elderly and students in the metro ridership is much smaller than the proportion of the actual population in our data set. Therefore, we have not only used the negative binomial regression model to explore the influence of the built environment on the metro usage of the three groups but have also used the fractional response model to explore factors that increase the share of the elderly and students in the metro ridership. In our results, most variables are positively attractive to specific groups but have significant differences in their influence on the market share of the elderly and students. This conclusion provides new ideas for increasing the metro ridership and reducing the gap in allocating public transportation resources. For example, the number of schools in the catchment area of the metro station not only enhances the metro ridership but also increases the proportion of the elderly and students in the metro ridership.

We found that the distribution of travel time of the three groups of people showed morning and evening peaks, but the peak travel time of students is earlier than that of adults. As the elderly have more free time, they also have more trips between 9:00 and 15:00. These conclusions help policymakers understand the travel differences of different groups and formulate diversified metro ticket prices and operation plans to meet the travel demands of specific groups; for instance, to alleviate the travel conflicts between the elderly and other people during the morning peak periods. The government can appropriately reduce the ticket price discount for the elderly during peak periods and encourage them to take more trips during off-peak periods. At the same time, policymakers should consider shortening students' travel time and distance through good urban planning schemes and education management to ensure the healthy growth of children.

Among all the station characteristics, the number of bus stops is the only factor that increases the number of metro trips and the market share of students. The result means that in future transportation planning, policymakers can plan some bus routes near high-density children's residences and schools to facilitate students' changes of transportation mode. In addition, we found that metro stations located in the main urban area with many entrances/exits can significantly attract more elderly and student passengers. This discovery is crucial and provides a reference for policymakers to increase metro ridership from the metro line design and station characteristics.

The study found that the number of schools around metro stations significantly increased students' usage and share of the metro ridership. Surprisingly, the factor also positively influences the number and proportion of metro trips by the elderly. Therefore, policymakers should consider improving the travel environment of schools near metro stations to facilitate the travel of students and the elderly. Moreover, we found that the number of hospitals, supermarkets, squares, parks, and scenic spots is significantly and positively associated with the elderly metro usage and the market share of the elderly. These results indicate that the metro is essential for maintaining the quality of older adults' daily lives. In response to the increase in the aging society, policymakers should consider building metro stations near the elderly community and elderly care homes to maintain the necessary mobility of the elderly.

The study has some limitations. First, although we explored the travel time distribution of adults, senior citizens, and students using the metro, we did not consider the impact of date attributes on the three groups of people. In the future, 
we should collect long-period metro smart card data to analyze the travel characteristics of various people on weekdays, weekends, and holidays. Second, due to the limitations of the data set, we did not consider the family characteristics of the studied groups. The next step should be to design a detailed family survey questionnaire covering family members, family income, and car ownership for further research.

\section{Data Availability}

The metro smart card data used to support the findings of this study are available from the corresponding author upon request. The point of interest (POI) data taken from the Baidu map are available at https://map.baidu.com/.

\section{Conflicts of Interest}

The authors declare that they have no conflicts of interest.

\section{Acknowledgments}

This study was financially supported by the National Natural Science Foundation of China (Grant no. 51878062), and the Higher Education Discipline Innovation Project 111 (Grant no. B20035).

\section{Supplementary Materials}

Table S1: the metro smart card data structure. (Supplementary Materials)

\section{References}

[1] J. Zhao, W. Deng, Y. Song, and Y. Zhu, "What influences Metro station ridership in China? Insights from Nanjing," Cities, vol. 35, pp. 114-124, 2013.

[2] China Association of Metros, Statistics and Analysis Report of Urban Rail Transit in 2020, China Association of Metros, Beijing, China, 2021, https://www.camet.org.cn/tjxx/7647.

[3] M. G. McNally, "The four-step model," in Handbook of Transport Modelling, The Four-step Model, D. A. Hensher and K. J. Button, Eds., vol. 1, pp. 35-53, Emerald Group Publishing Limited, Bingley, England, 2007.

[4] S. Rasouli and H. Timmermans, "Activity-based models of travel demand: promises, progress and prospects," International Journal on the Unity of the Sciences, vol. 18, no. 1, pp. 31-60, 2014.

[5] J. L. Bowman and M. E. Ben-Akiva, "Activity-based disaggregate travel demand model system with activity schedules," Transportation Research Part a: Policy and Practice, vol. 35, no. 1, pp. 1-28, 2001.

[6] J. Gutiérrez, O. D. Cardozo, and J. C. García-Palomares, "Transit ridership forecasting at station level: an approach based on distance-decay weighted regression," Journal of Transport Geography, vol. 19, no. 6, pp. 1081-1092, 2011.

[7] O. D. Cardozo, J. C. García-Palomares, and J. Gutiérrez, "Application of geographically weighted regression to the direct forecasting of transit ridership at station-level," Applied Geography, vol. 34, pp. 548-558, 2012.

[8] J. Zhao, W. Deng, Y. Song, and Y. Zhu, "Analysis of Metro ridership at station level and station-to-station level in
Nanjing: an approach based on direct demand models," Transportation, vol. 41, no. 1, pp. 133-155, 2014.

[9] M. Kuby, A. Barranda, and C. Upchurch, "Factors influencing light-rail station boardings in the United States," Transportation Research Part A: Policy and Practice, vol. 38, no. 3, pp. 223-247, 2004.

[10] K. Sohn and H. Shim, "Factors generating boardings at metro stations in the Seoul metropolitan area," Cities, vol. 27, no. 5, pp. 358-368, 2010.

[11] R. Guo and Z. Huang, "Mass rapid transit ridership forecast based on direct ridership models: a case study in wuhan, China," Journal of Advanced Transportation, vol. 2020, p. 19, Article ID 7538508, 2020.

[12] F. Shao, Y. Sui, X. Yu, and R. Sun, "Spatio-temporal travel patterns of elderly people - a comparative study based on buses usage in Qingdao, China," Journal of Transport Geography, vol. 76, pp. 178-190, 2019.

[13] S. Zhang, Y. Yang, F. Zhen, T. Lobsang, and Z. Li, "Understanding the travel behaviors and activity patterns of the vulnerable population using smart card data: an activity space-based approach," Journal of Transport Geography, vol. 90, Article ID 102938, 2021.

[14] R. Alsnih and D. A. Hensher, "The mobility and accessibility expectations of seniors in an aging population," Transportation Research Part a: Policy and Practice, vol. 37, no. 10, pp. 903-916, 2003.

[15] D. Julien, L. Richard, L. Gauvin et al., “Transit use and walking as potential mediators of the association between accessibility to services and amenities and social participation among urban-dwelling older adults: insights from the VoisiNuAge study," Journal of Transport \& Health, vol. 2, no. 1, pp. 35-43, 2015.

[16] W. Y. Szeto, L. Yang, R. C. P. Wong, Y. C. Li, and S. C. Wong, "Spatio-temporal travel characteristics of the elderly in an ageing society," Travel Behaviour and Society, vol. 9, pp. 1020, 2017.

[17] S. Y. He, Y. H. Y. Cheung, and S. Tao, "Travel mobility and social participation among older people in a transit metropolis: a socio-spatial-temporal perspective," Transportation Research Part A: Policy and Practice, vol. 118, pp. 608-626, 2018.

[18] L. Cheng, X. Chen, S. Yang, Z. Cao, J. De Vos, and F. Witlox, "Active travel for active ageing in China: the role of built environment," Journal of Transport Geography, vol. 76, pp. 142-152, 2019.

[19] J. Feng, "The influence of built environment on travel behavior of the elderly in urban China," Transportation Research Part D: Transport and Environment, vol. 52, pp. 619-633, 2017.

[20] L. Cheng, J. De Vos, K. Shi, M. Yang, X. Chen, and F. Witlox, "Do residential location effects on travel behavior differ between the elderly and younger adults?" Transportation Research Part D: Transport and Environment, vol. 73, pp. 367-380, 2019.

[21] M. Winters, C. Voss, M. C. Ashe, K. Gutteridge, H. McKay, and J. Sims-Gould, "Where do they go and how do they get there? Older adults' travel behaviour in a highly walkable environment," Social Science \& Medicine, vol. 133, pp. 304-312, 2015.

[22] A. Ståhl and M. Berntman, "Falls in the outdoor environment among older persons-a tool to predict accessibility," in Proceedings of the 11th International Conference on Mobility and Transport for Elderly and Disabled Persons, Montréal, Canada, January 2007. 
[23] Y. Zhang, E. Yao, R. Zhang, and H. Xu, "Analysis of elderly people's travel behaviours during the morning peak hours in the context of the free bus programme in Beijing, China," Journal of Transport Geography, vol. 76, pp. 191-199, 2019.

[24] S. Rosenbloom, "Sustainability and automobility among the elderly: an international assessment," Transportation, vol. 28, no. 4, pp. 375-408, 2001.

[25] L. T. Truong and S. V. C. Somenahalli, "Exploring frequency of public transport use among older adults: a study in Adelaide, Australia," Travel Behaviour and Society, vol. 2, no. 3, pp. 148-155, 2015.

[26] M. Du, L. Cheng, X. Li, and J. Yang, "Factors affecting the travel mode choice of the urban elderly in healthcare activity: comparison between core area and suburban area," Sustainable cities and society, vol. 52, Article ID 101868, 2020.

[27] A. Broberg and S. Sarjala, "School travel mode choice and the characteristics of the urban built environment: the case of Helsinki, Finland," Transport Policy, vol. 37, pp. 1-10, 2015.

[28] R. Ewing, W. Schroeer, and W. Greene, "School location and student travel analysis of factors affecting mode choice," Transportation Research Record, vol. 1895, no. 1, pp. 55-63, 2004.

[29] R. Zhang, E. Yao, and Z. Liu, "School travel mode choice in Beijing, China," Journal of Transport Geography, vol. 62, pp. 98-110, 2017.

[30] Y. Liu, Y. Ji, Z. Shi, and L. Gao, "The influence of the built environment on school children's metro ridership: an exploration using geographically weighted Poisson regression models," Sustainability, vol. 10, no. 12, Article ID 4684, 2018.

[31] J. A. Kelly and M. Fu, "Sustainable school commuting understanding choices and identifying opportunities," Journal of Transport Geography, vol. 34, pp. 221-230, 2014.

[32] S. Li and P. Zhao, "The determinants of commuting mode choice among school children in Beijing," Journal of Transport Geography, vol. 46, pp. 112-121, 2015.

[33] K. Y. K. Leung and B. P. Y. Loo, “Determinants of children's active travel to school: a case study in Hong Kong," Travel Behaviour and Society, vol. 21, pp. 79-89, 2020.

[34] A. Ermagun and A. Samimi, "Promoting active transportation modes in school trips," Transport Policy, vol. 37, pp. 203-211, 2015.

[35] S. Y. He and G. Giuliano, "School choice: understanding the trade-off between travel distance and school quality," Transportation, vol. 45, no. 5, pp. 1475-1498, 2018.

[36] M. Palm and S. Farber, "The role of public transit in school choice and after-school activity participation among Toronto high school students," Travel Behaviour and Society, vol. 19, pp. 219-230, 2020.

[37] Qingdao Statistics Bureau, Qingdao National Economic and Social Development Statistics Bulletin, Qingdao Statistics Bureau, Qingdao, China, 2020, https://qdtj.qingdao.gov.cn/ n28356045/n32561056/n32561070/200327102041515838. html.

[38] Ministry of Construction P.R.China, China Urban Construction Statistical Yearbook, Ministry of Construction P.R.China, Beijing, China, 2020, http://www.mohurd.gov.cn/ xytj/tjzljsxytjgb/jstjnj/.

[39] S. Li, D. Lyu, X. Liu et al., "The varying patterns of rail transit ridership and their relationships with fine-scale built environment factors: big data analytics from Guangzhou," Cities, vol. 99, Article ID 102580, 2020.

[40] S. Washington, M. Karlaftis, F. Mannering, and P. Anastasopoulos, Statistical and Econometric Methods for Transportation Data Analysis, CRC Press, FL, USA, 2020.
[41] L. E. Papke and J. M. Wooldridge, "Econsometric methods for fractional response variables with an application to $401(\mathrm{k})$ plan participation rates," Journal of Applied Econometrics, vol. 11, no. 6, pp. 619-632, 1996.

[42] N. C. McDonald, Y. Yang, S. M. Abbott, and A. N. Bullock, "Impact of the safe routes to school program on walking and biking: eugene, Oregon study," Transport Policy, vol. 29, pp. 243-248, 2013.

[43] K. Wang and G. Akar, "Gender gap generators for bike share ridership: evidence from Citi Bike system in New York City," Journal of Transport Geography, vol. 76, pp. 1-9, 2019.

[44] L. E. Papke and J. M. Wooldridge, "Panel data methods for fractional response variables with an application to test pass rates," Journal of Econometrics, vol. 145, no. 1-2, pp. 121-133, 2008.

[45] D. An, X. Tong, K. Liu, and E. H. W. Chan, "Understanding the impact of built environment on metro ridership using open source in Shanghai," Cities, vol. 93, pp. 177-187, 2019.

[46] M.-J. Jun, K. Choi, J.-E. Jeong, K.-H. Kwon, and H.-J. Kim, "Land use characteristics of subway catchment areas and their influence on subway ridership in Seoul," Journal of Transport Geography, vol. 48, pp. 03-40, 2015.

[47] G. Gao, Z. Wang, X. Liu, Q. Li, W. Wang, and J. Zhang, "Travel behavior analysis using 2016 Qingdao's household traffic surveys and Baidu electric map API data," Journal of Advanced Transportation, vol. 2019, p. 18, Article ID 6383097, 2019. 